\title{
Altered expression of two light-dependent genes in a microcystin-lacking mutant of Microcystis aeruginosa PCC 7806
}

\author{
Elke Dittmann, ${ }^{1}$ Marcel Erhard ${ }^{2}$ Melanie Kaebernick, ${ }^{1,3}$ \\ Christian Scheler, ${ }^{2}$ Brett A. Neilan, ${ }^{3}$ Hans von Döhren ${ }^{2}$ \\ and Thomas Börner ${ }^{1}$
}

Author for correspondence: Elke Dittmann. Tel: +49 302093 8145. Fax: +49 3020938141. e-mail : elke=dittmann@ rz.hu-berlin.de

\footnotetext{
1 Institute for Biology (Genetics), Humboldt University, Chausseestr. 117, 10115 Berlin, Germany

2 Institute for Biochemistry and Molecular Biology, Technical University, Franklinstr. 29, 10587 Berlin, Germany

3 School of Microbiology and Immunology, University of NSW, Sydney, NSW 2052, Australia
}

\begin{abstract}
Microcystin is a potent inhibitor of eukaryotic protein phosphatases and has been implicated in causing hepatotoxicity to humans and animals worldwide. It is produced primarily by the bloom-forming cyanobacterium Microcystis aeruginosa, although the function of the peptide in this micro-organism is unknown. In this study, a microcystin-related protein, MrpA, was identified using a microcystin-lacking mutant of $M$. aeruginosa, PCC 7806. Comparative two-dimensional protein electrophoresis showed that MrpA was strongly expressed in wild-type PCC 7806, but was not detectable in the mcyB mutant. MrpA showed similarity to the RhiA protein from Rhizobium leguminosarum, which is encoded by the rhiABC operon and controlled by quorum-sensing mediators. Sequencing of mrpA flanking regions in M. aeruginosa PCC 7806 revealed the presence of a rhiB homologue, $\operatorname{mrpB}$, directly downstream of mrpA. Northern blot analyses of $m r p A$ expression in cells exposed to different light conditions revealed a rapid decline of transcription under high light conditions. Most striking was a strong increase in transcript levels from cultures irradiated with blue light. The mrpA transcription level was strongly reduced in two independent microcystin-lacking mutants under all light conditions investigated.
\end{abstract}

Keywords: RhiA, transcription, endotoxin, Rhizobium leguminosarum

\section{INTRODUCTION}

Cyanobacteria (blue-green algae) are a particularly rich source of bioactive secondary metabolites, including peptides, polyketides and alkaloids. Under favourable environmental conditions these algae grow to such an extent that blooms develop. The toxic metabolites produced by these blooms have been implicated in serious health problems, and even death in humans and animals (Carmichael, 1994; Jochimsen et al., 1998; Namikoshi \& Rinehart, 1996).

Among the secondary metabolites synthesized by bloom-forming cyanobacteria the potent hepatotoxin

Abbreviations: Adda, (2S,3S,8S,9S)-3-amino-9-methoxy-2,6,8,-trimethyl10-phenyl-4,6-decadienoic acid; MALDI-TOF, matrix-assisted laser desorption/ionization-time of flight spectroscopy; Mdha, N-methyldehydroalanine; TFA, trifluoroacetic acid.

The GenBank accession number for the sequence reported in this paper is AJ271976. microcystin has been most extensively investigated. More than 60 isoforms of this heptapeptide are currently known, sharing the structure cyclo(-D-Ala-L-X-DMeAsp-L-Z-Adda-D-Glu-Mdha), where $X$ and $Z$ represent variable L-amino acids. Microcystins are specific inhibitors of the eukaryotic protein phosphatases 1 and 2A (Runnegar et al., 1993), but not of a similar cyanobacterial protein phosphatase (Shi et al., 1999). They are synthesized by various cyanobacterial freshwater species belonging to the genera Microcystis, Anabaena, Oscillatoria and Nostoc (Chorus \& Bartram, 1999). Microcystis aeruginosa, which is the most widely distributed microcystin-producing species, also synthesizes other peptides, including the depsipeptides cyanopeptolin and micropeptin, the tricyclic microviridins, and the linear microginins and aeruginosins. Most of these peptides are protease inhibitors (Namikoshi \& Rinehart, 1996), and the majority of Microcystis strains naturally synthesize more than one of these compounds. 
The role of microcystin within the producing organism has not been elucidated. However, as its function is likely to be related to the conditions that enhance the production of peptides, factors such as culture age, temperature, light, nutrient, salinity, $\mathrm{pH}$ and micronutrient concentrations have been investigated and shown to affect the microcystin content of M. aeruginosa, Anabaena flos-aquae and Oscillatoria agardhii (Chorus \& Bartram, 1999). A correlation between microcystin production and growth rate, regardless of environmental influences, has also been reported (Orr \& Jones, 1998). However, with the inability to compare results from various studies due to different culturing and analysis methods used, no conclusions can be made about the effect of growth rate or environmental factors regulating toxin production. More recently, molecular techniques have been employed to show an effect of light on microcystin biogenesis in two strains of M. aeruginosa (Nishizawa et al., 1999; Kaebernick et al., 2000).

So far detailed investigations into the function of microcystin and other similar cyanobacterial secondary metabolites have been hampered by the lack of clearly defined mutants incabable of producing one of these substances. Microcystis spp. may produce a number of secondary metabolites but biosynthesis genes have only been identified for microcystin. The toxin microcystin is synthesized non-ribosomally via a giant multifunctional enzyme complex (microcystin synthetase), which includes peptide synthetases, polyketide synthases and modifying activities (Dittmann et al., 1997; Nishizawa et al., 1999, 2000; Tillett et al., 2000). Three of the genes (mcyA, $m c y B$ and $m c y D)$ involved in microcystin synthetase production in M. aeruginosa PCC 7806 have been insertionally inactivated and the respective mutants are characterized by the complete absence of all variants of microcystin. The mutants lack the whole microcystin synthetase complex, but still produce other nonribosomal peptides (Dittmann et al., 1997; Tillett et al., 2000). These mutants are ideal subjects for studying the function(s) of microcystins.

Putative roles for microcystin have been suggested (Chorus \& Bartram, 1999; Rohrlack et al., 1999): as a feeding deterrent against zooplankton, a suppressor of the growth of competing species, or as an ironscavenging molecule. Most of these functions, and those investigated for secondary metabolites in other bacteria and fungi, are usually linked with export of the substance from the cells under certain environmental conditions or growth states (Perry et al., 1999; Pitkin et al., 1996). In contrast to most microbial secondary metabolites, microcystins are produced from early exponential phase to stationary phase and are regarded as endotoxins (Chorus \& Bartram, 1999). According to most recent data, however, an ABC-transporter protein is encoded as part of the gene cluster for microcystin biosynthesis (Tillett et al., 2000). This protein may play a role in the active export of microcystins from the cells. So far, microcystin detected outside the cells in the culture medium, under high light, has largely been attributed to cell lysis (Rapala et al., 1997). Yet this may also suggest an export, and point to an extracellular role for microcystin under these conditions (Kaebernick et al., 2000; E. Dittmann \& M. Kaebernick, unpublished data).

Here we describe a molecular approach to the elucidation of microcystin function. A protein of approximately $30 \mathrm{kDa}$ was found to be strongly expressed in wild-type cells, but was not detectable in protein preparations from $m c y B$ mutant cells. It is similar to the RhiA protein from Rhizobium leguminosarum. Expression of RhiA is cell-density-dependent and involves quorum-sensing mediators. Transcriptional analysis of the 'Microcystis' homologue indicates regulation by light.

\section{METHODS}

Cyanobacterial strains and culturing. The microcystin-producing strain M. aeruginosa PCC 7806 was kindly provided by J. Weckesser (Freiburg University, Freiburg i.Br., Germany) and R. Rippka (Institut Pasteur, Paris, France). Mutants of this strain unable to produce microcystins were obtained by natural transformation and insertion of a chloramphenicolresistance cartridge into the peptide synthetase genes $m c y B$ (Dittmann et al., 1997) and mcyA (Tillett et al., 2000). Wildtype and mutant cell lines were grown at $23{ }^{\circ} \mathrm{C}$ in batch cultures with BG-11 or Z8 medium (Rippka, 1988), respectively. The mutants used in this study were selected and kept on BG-11 medium containing $5 \mu \mathrm{g}$ chloramphenicol $\mathrm{ml}^{-1}$ (Dittmann et al., 1997). For comparative studies of the two variants chloramphenicol was removed from the mutant medium in order to exclude any influence the antibiotic may have had on physiological processes. Growth of the wild-type and the mutant strains was followed by monitoring the $\mathrm{OD}_{750}$ with a Uvikon 930 spectrometer (Contron Instruments) and the cell number by microscopic counting using a haemocytometer (Thoma). Cells were grown under $16 \mu \mathrm{mol}$ photons $\mathrm{m}^{-2} \mathrm{~s}^{-1}$ white light (low light), $5 \mu \mathrm{mol}$ photons $\mathrm{m}^{-2} \mathrm{~s}^{-1}$ (very low light) or $68 \mu \mathrm{mol}$ photons $\mathrm{m}^{-2} \mathrm{~s}^{-1}$ (high light). Light intensities were measured using a LI-COR LI-250 light meter (Walz). Different light qualities were obtained by the use of blue and red plastic cut-off filters (Lee Filters). The blue light filter had a bandwidth of $400-510 \mathrm{~nm}$ with a peak at $472 \mathrm{~nm}$ and the red filter opened from $620 \mathrm{~nm}$ with $\tau_{1 / 2}$ at $666 \mathrm{~nm}$. For both cases a light intensity of $16 \mu \mathrm{mol}$ photons $\mathrm{m}^{-2} \mathrm{~s}^{-1}$ was applied in a dark room using a Fibre Illuminator FL-440 (Walz) and unilateral irradiation.

Two-dimensional gel electrophoresis. This was performed as described by Otto et al. (1996) as modified by Scheler et al. (1998), using the Bio-Rad 2-D system. Twenty milligrams of dried cells was suspended in sonication buffer $[9 \mathrm{M}$ urea, $70 \mathrm{mM}$ DTT and $2 \%$ ampholyte (Serva 2-4)] and sonicated for $5 \mathrm{~min}$. After centrifugation $(12000 \mathrm{~g}, 10 \mathrm{~min})$ the first dimension (IF) was performed in a glass tube $(0.15 \mathrm{~cm} \times 9.3 \mathrm{~cm})$ using $20 \mu \mathrm{g}$ of the protein extract. For the second dimension the IF gel was incubated with loading buffer for $15 \mathrm{~min}$ and subsequently loaded onto a $10 \%$ SDS-PAGE gel. Gels were stained with Coomassie R 250.

Isolation of a two-dimensional spot and sequence analysis of peptides. Protein was isolated from a spot as described by Otto et al. (1996) and Scheler et al. (1998). The protein was digested with trypsin $(1 \mu \mathrm{g}$ in $600 \mu$ l digestion buffer; $100 \mathrm{mM}$ Tris $/ \mathrm{HCl} \mathrm{pH} 8.5$ in $50 \%$ acetonitrile) overnight at $37^{\circ} \mathrm{C}$. The reaction was stopped with $2 \% \operatorname{TFA}\left(1 \mathrm{~h}, 60^{\circ} \mathrm{C}\right)$ and the gel was mixed with reversed-phase material (Scheler et al., 1998). 
After binding ( $0 \cdot 1 \%$ TFA) and washing ( $0 \cdot 1 \%$ TFA) peptides were eluted with elution buffer $(60 \%$ acetonitrile in $0.1 \%$ TFA). Peptides were separated using a FPLC chromatography system (Pharmacia), analysed by MALDI-TOF (Perseptive Biosystems) and sequenced using the Procise Protein Sequencing system (Applied Biosystems).

Degenerate PCR and sequencing, partial genomic library. The two primer pairs Deg1F/Deg2R (5'-GTNGTNATHGAYAAYTTY-3' $/ 5^{\prime}$-RTTRAARTCNACRTARTA-3') and Deg2F/Deg1R (5'-TAYTAYGTNGAYTTYAAY-3'/5'-RAARTTGTCDATNACNAC-3') were designed from the peptide fragments LIAQAANVVIDNFSSFDQ and TYYVDFNNQTDR. PCR was performed using Qiataq (Qiagen) and $45^{\circ} \mathrm{C}$ as the annealing temperature. A number of bands from both amplifications were eluted from the gel and inserted into the pGem-T vector (Promega) according to the manufacturer's instructions. Sequence reactions were carried out using a Dyedeoxy Terminator Cycle Sequencing Kit (Applied Biosystems) and analysed on an automated DNA sequencer (model 373; Applied Biosystems). Southern blotting and the construction and screening of a partial $(X b a I)$ library in pUC19 were performed as described by Sambrook et al. (1989).

RNA isolation and Northern blot hybridization. For RNA isolations $30-50 \mathrm{ml}$ cultures (mid-exponential phase; $\mathrm{OD}_{750}$ $0 \cdot 7-1 \cdot 0)$ were immediately chilled under the particular light conditions being investigated. Cultures were centrifuged $\left(2770 \mathrm{~g}, 10 \mathrm{~min}, 4^{\circ} \mathrm{C}\right.$ ) and stored at $-20^{\circ} \mathrm{C}$. The pellet was homogenized in liquid nitrogen using a pestle and mortar. RNAs were isolated using the Trizol kit (Gibco-BRL) according to the manufacturer's instructions. RNA was further purified using the High Pure RNA isolation kit (BoehringerMannheim) following the associated instructions. RNA gel electrophoresis, Northern blotting and hybridization were performed as described by Sambrook et al. (1989). Probes to the $p s b B$ gene fragment of Synechocystis PCC 6803 were kindly provided by Dr Annegret Wilde (Humboldt University, Berlin, Germany). A gene fragment of the $c p c$ operon of PCC 7806 was amplified using the primer pair $\mathrm{PC} \beta \mathrm{F}$ and $\mathrm{PC} \alpha \mathrm{R}$ (Neilan et al., 1995) and the 825 bp mrpA PCR fragment cloned into the pGEM-T vector (see above) was used as a $m r p A$ probe. A $m r p B$ probe was amplified using the primer pair mdpBF (5'-CATACGGTTGGATGTTGTGC-3') and mdpBR (5'-CATTCCCTCTGGTCCAATTC-3'). The $16 \mathrm{~S}$ rRNA fragment for use as a probe was amplified using the primer pair 16SF (5'-TGTAAAACGACGGCCAGTGAAGTCGTAACAAGC-3') and 16SR (5'-TAGCAGGAAACAGCTATGACCCTCTGTGTGCCTAGGTATCC-3'). The reverse transcription was performed using an RT kit (GibcoBRL) according to the manufacturer's instructions. Prior to the reaction RNA was further purified using DNase I (GibcoBRL). The mrpBRT primer (5'-CAAGCTCTCAGCCTGTGCATTC-3') was used as a gene-specific reverse primer. The subsequent PCR was performed with DNA, DNA-free RNA, as a positive and a negative control, respectively, and cDNA with the primer mrpBRT and the primer $\mathrm{MB} 35 / 63 \mathrm{~F}\left(5^{\prime}-\right.$ GAAGGTGAGTCCAGTGTTGATG-3').

\section{RESULTS}

\section{Identification of the differentially expressed MrpA protein}

In order to compare the proteomes of $M$. aeruginosa PCC 7806 and the microcystin-lacking $m c y B$ mutant (Dittmann et al., 1997) we performed two-dimensional protein electrophoresis. Visual analysis revealed several qualitative and quantitative differences between the wild-type and mutant. A protein of approximately $30 \mathrm{kDa}$ was strongly expressed in the wild-type extract, but was not detectable in the mutant extract (Fig. 1a, b). At least three more proteins showed different abundances. Two $(22 \mathrm{kDa}, 25 \mathrm{kDa})$ were more strongly and one $(40 \mathrm{kDa})$ was more weakly expressed in the $m c y B$ mutant. The most prominent protein, of approximately $30 \mathrm{kDa}$, was extracted from the gel and trypsinized for further analysis. Tryptic peptides were purified and fractionated using MALDI-TOF and FPLC. Four of the resulting peptides were subsequently sequenced (Fig. 1c). A BLAST (http://www.ncbi.nlm.nih.gov/blast/ blast.cgi) search of these peptides against the complete proteome of Synechocystis sp. PCC 6803 (Kaneko et al., 1995) revealed no significant homologies and a search against the entire Synechocystis database indicated that this was not a conserved protein among cyanobacteria.

The sequence information from peptides 1 and 2 (Fig. 1c) was used to design degenerate PCR primers, as these sequences had the lowest degree of redundancy in their amino acid composition. As the order of the peptides in the protein was unknown, two complementary primer pairs were synthesized. Both pairs yielded a number of PCR products (data not shown). Three abundant bands from each of the two PCR approaches were eluted from the agarose gel and inserted into the pGem-T vector. Sequencing of a number of clones revealed an $825 \mathrm{bp}$ PCR product encoding a protein starting with the sequence TYYVDFNNQTDR and terminating with the sequence LIAQAANVVIDNFSSFDQ. Further sequence analysis of the whole clone led to the identification of a continuous ORF encoding a protein with identity to all partial peptides we had sequenced before. The $825 \mathrm{bp}$ sequence encodes a protein of approximately $30 \mathrm{kDa}$ that represents the major part of the gene encoding the microcystin-related protein, MrpA. A BLAST search revealed $42 \%$ similarity and $23 \%$ identity of the $\mathrm{N}$ terminus to RhiA from $R$. leguminosarum. Further homologues of the mrpA gene were identified in the complete genomes of Yersinia pestis and Yersinia pseudotuberculosis (http://pedant.gsf.de/).

To complete the sequence encoding MrpA, and to identify neighbouring genes, we established a partial genomic library of strain PCC 7806. Using Southern blot hybridization with the $825 \mathrm{bp}$ PCR fragment as a probe we identified a single $3.4 \mathrm{~kb} X b a \mathrm{I}$ fragment. Based on this information, $X b a I$ fragments with a size range of $3 \cdot 2-3.7 \mathrm{~kb}$ were cloned after insertion into a predigested pUC19/XbaI vector. Subsequently, a positive Escherichia coli clone containing a $3.4 \mathrm{~kb}$ fragment of $M$. aeruginosa DNA was identified by colony hybridization. The sequence was determined for both strands and has been deposited in the EMBL/GenBank database under the accession number AJ271976.

Analysis of the $3.4 \mathrm{~kb}$ DNA fragment revealed the presence of three ORFs, designated $m r p A, m r p B$ and ORF3. The molecular mass of MrpA was determined to be $35.9 \mathrm{kDa}$ (pI 5.11). The second ORF, $\operatorname{mrpB}$, was 
(a)

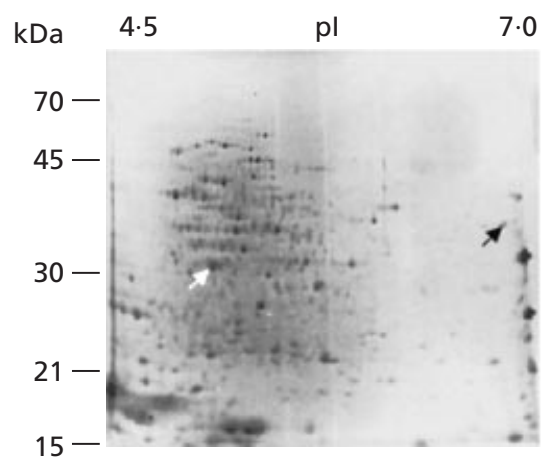

(b)

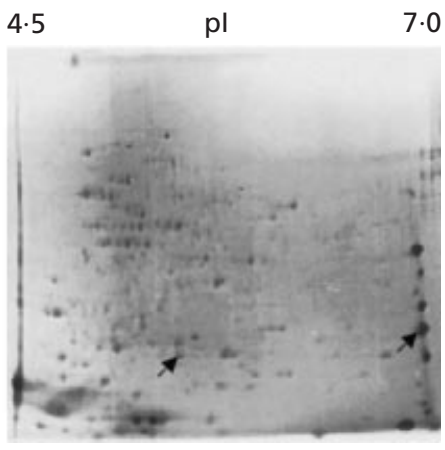

Fig. 1. Two-dimensional protein maps of (a) wild-type $M$. aeruginosa PCC 7806 and (b) the mcyB mutant (Dittmann et al., 1997). Protein extracts were isolated from lateexponential phase cultures. Positions of qualitative and quantitative differences are indicated. The white arrow denotes a protein spot of approximately $30 \mathrm{kDa}$ which was predominantly expressed in the wild-type PCC 7806, but not detectable in the mcyB mutant. This protein has been designated MrpA (microcystin-related protein A). Black arrows indicate further differentially expressed proteins. (c) Partial peptide sequences derived from tryptic digestion of the MrpA protein.

\section{TYYVDFNNQTDR \\ 2. LIAQAANVVIDNFSSFDQXA \\ 3. FNNIQLGTKK \\ 4. DVLSSSSAQFK}

located $117 \mathrm{bp}$ downstream of $m r p A$. Its deduced amino acid sequence exhibits $71 \%$ similarity and $56 \%$ identity to RhiB. RhiB is encoded together with RhiA and a third protein, $\mathrm{RhiC}$, in the rhiABC operon of $R$. leguminosarum. The molecular mass of MrpB was calculated to be $15.8 \mathrm{kDa}$ with a $\mathrm{pI}$ of $4 \cdot 47$. A protein with a $\mathrm{pI}$ in this range was not detectable by two-dimensional gel electrophoresis under the conditions used in this study. The third ORF was located 275 bp downstream of $m r p B$ on the same DNA strand. Database analysis of this ORF did not show significant similarity to known proteins. Analysis of MrpA and MrpB, using Prosite and the PSORT software, detected no significant matches with motifs in the database for MrpA; however, a possible ATP/GTP binding motif (P-loop) was observed in MrpB. MrpA is predicted to be a cytosolic protein, as is its homologue in Rhizobium. Cytosolic localization was also predicted for MrpB, with a lower value compared to MrpA.

\section{Transcript analyses}

To investigate whether different amounts of MrpA in wild-type and mutant cells correlate with altered transcript levels we performed Northern blot hybridizations with a fragment of $m r p A$ as the probe. High amounts of a transcript of approximately $1.5 \mathrm{~kb}$ were detected in RNA preparations from the wild-type, compared to the reduced level found in samples prepared from mutant cells (Fig. 2). As already suggested by its length, this transcript also hybridized with a $m r p B$ probe, therefore indicating a bicistronic messenger (data not shown). The same RNA samples were used to compare the abundances of $c p c B A$ and $p s b B$ transcripts, encoding proteins of the light-harvesting antennae and of the photosystem II reaction centre, respectively. For both transcripts, no differences between wild-type and mutant cells were observed. In all cases $16 \mathrm{~S}$ rRNA served as an internal standard (Fig. 2). The co-transcription of
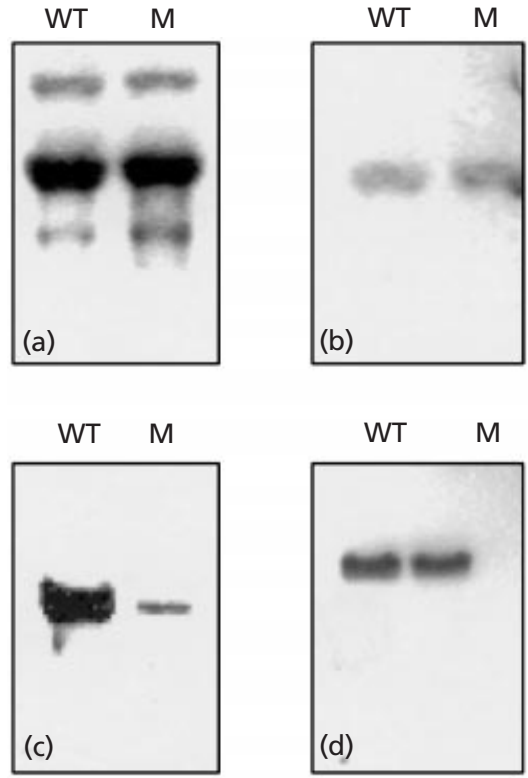

Fig. 2. Northern blot analysis of $M$. aeruginosa PCC 7806 (WT) and $m c y B$ mutant (M) RNA isolated from late-exponentialphase cultures under medium light condition $(20 \mu \mathrm{g}$ RNA per lane). DNA fragments of (a) $c p c B A$, (b) psbB, (c) $m r p A$ and (d) $M$. aeruginosa $16 \mathrm{~S}$ rRNA served as probes.

$m r p A$ and $m r p B$ was confirmed by RT-PCR (Fig. 3). The intergenic region between $m r p A$ and $m r p B$ was successfully amplified from cDNA using a primer pair binding to $m r p A$ and $m r p B$, respectively.

The rhiABC transcription in $R$. leguminosarum was shown to be under the control of quorum-sensing mediators, therefore showing a strong increase in the stationary phase (Rodelas et al., 1999). In contrast, the $m r p A B$ transcript did not show significant differences at different time points of the growth curve (data not 


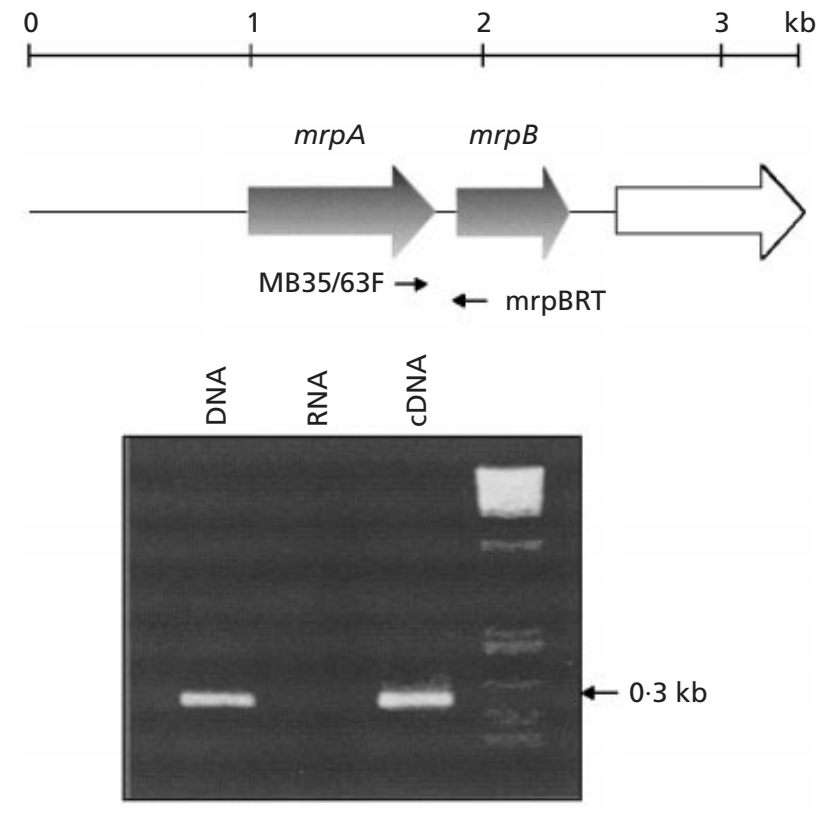

Fig. 3. $P C R$ amplification with the primer pair $M B 35 / 63 F$ and mbpBRT, using DNA, DNA-free RNA and CDNA of $M$. aeruginosa PCC 7806 as templates. CDNA was prepared by reverse transcription with the gene-specific reverse primer mbpBRT.

shown). Genes of the microcystin biosynthesis gene cluster are differentially expressed under various light intensites and qualities (Kaebernick et al., 2000). With the possibility of an influence of microcystin on MrpAB production, we also studied the response of $m r p A B$ transcripts to different light quantities and qualities. Wild-type PCC 7806 was cultured to mid-exponential phase $\left(\mathrm{OD}_{750} 0 \cdot 66\right)$ under low light conditions $(16 \mu \mathrm{mol}$ photons $\mathrm{m}^{-2} \mathrm{~s}^{-1}$ ). Subsequently, aliquots were exposed, for $30 \mathrm{~min}$ or $2 \mathrm{~h}$, to different quantities of white light $\left(16 \mu \mathrm{mol}\right.$ photons $\mathrm{m}^{-2} \mathrm{~s}^{-1}$, $68 \mu \mathrm{mol}$ photons $\mathrm{m}^{-2} \mathrm{~s}^{-1}$, $400 \mu \mathrm{mol}$ photons $\mathrm{m}^{-2} \mathrm{~s}^{-1}$ ), red light or blue light (each at $16 \mu \mathrm{mol}$ photons $\mathrm{m}^{-2} \mathrm{~s}^{-1}$ ) and complete darkness (Fig. 4a). RNA was isolated from each of the samples and analysed by Northern blot hybridization. Transcript amounts seen under low light $\left(16 \mu \mathrm{mol}\right.$ photons $\left.\mathrm{m}^{-2} \mathrm{~s}^{-1}\right)$ were almost abolished after $2 \mathrm{~h}$ of darkness, or exposure to high light and very high light $(68 \mu \mathrm{mol}$ photons $\mathrm{m}^{-2} \mathrm{~s}^{-1}$ and $400 \mu \mathrm{mol}$ photons $\mathrm{m}^{-2} \mathrm{~s}^{-1}$, respectively) (Fig. 4a). Most striking was the strong increase in the $m r p A B$ transcript level in cells exposed to blue light for $2 \mathrm{~h}$ (Fig. 3a). Results were standardized by hybridization with a DNA probe encoding the $16 \mathrm{~S}$ rRNA on the same total RNA samples (Fig. 4a). The microcystin-free $m c y B$ mutant, grown to mid-exponential phase and subsequently exposed to the same light conditions as above, revealed strongly reduced transcript amounts, even though a fourfold amount of RNA was used in Northern blot hybridizations. Interestingly, no significant differences in the transcript amounts were observed for the different light conditions (Fig. 4b). The same results were obtained for the mcyA
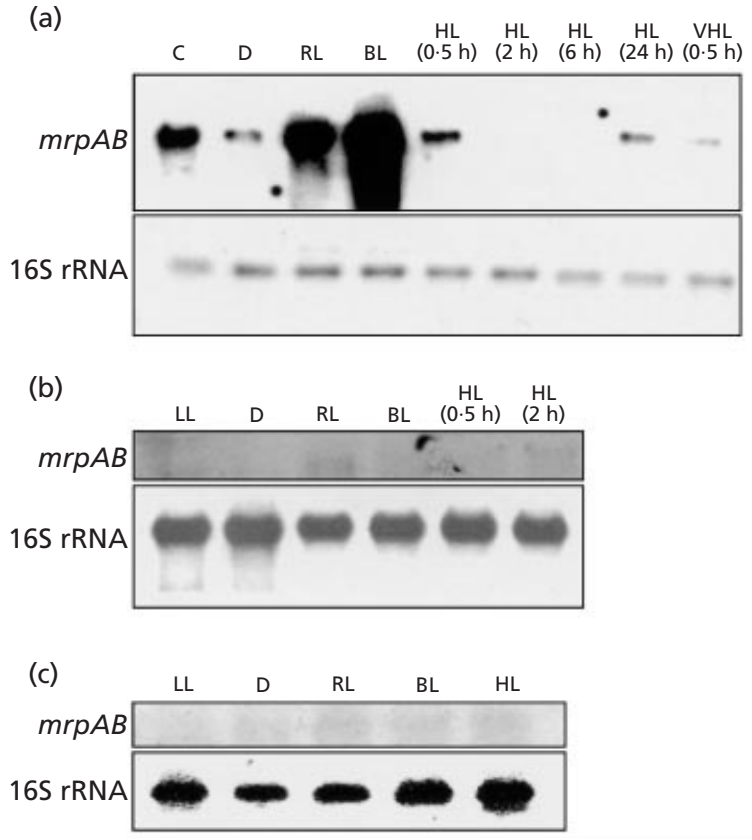

Fig. 4. Transcripts from cells grown to late-exponential phase under low light, and subsequently exposed for $0.5-24 \mathrm{~h}$ to different light conditions (cells were illuminated for $2 \mathrm{~h}$, unless indicated otherwise). Northern blot analysis for the presence of $m r p A B$ was done as follows. (a) Total RNA from wild-type PCC 7806 (5 $\mu \mathrm{g}$ RNA per lane). (b) Total RNA from mcyB mutant $(20 \mu \mathrm{g}$ RNA per lane). (c) Total RNA from mcyA mutant $(20 \mu \mathrm{g}$ RNA per lane). Hybridization with a DNA probe encoding the $16 \mathrm{~S}$ rRNA gene of $M$. aeruginosa was used on the total RNA of each of the samples to standardize the system. The light conditions used are indicated by: C, control (low light); D, dark; RL, red light; $B L$, blue light; $H L$, high light; $V H L$, very high light; LL, low light.

mutant (Fig. 4c). An extracellular microcystin proportion can be detected, especially under high light (E. Dittmann \& M. Kaebernick, unpublished data). In order to find out if this extracellular microcystin proportion could potentially influence the $m r p A B$ transcription (as seen for the rhiABC transcription in Rhizobium, which is strongly dependent on AHL mediators), $300 \mathrm{ng}$ microcystin $\mathrm{ml}^{-1}$ was added under low light and high light conditions to the $m c y B$ mutant culture. However, extracellular microcystin could not restore the wild-type transcription level (data not shown). All experiments with the wild-type and mutant strains were repeated twice, using independent material; reproducible results were obtained.

\section{DISCUSSION}

There has been considerable interest in understanding the function of microcystin for bloom-forming species of cyanobacteria. The microcystin-lacking $m c y B$ mutant opened a way for investigations into the role(s) such metabolites may play by enabling comparison of wildtype and mutant cells at the molecular level. This study describes the light-regulated $m r p A$ and $m r p B$ genes, 
which were previously thought to be unique to $R h i$ zobium, and shows that the expression of these genes, but not of other light-regulated genes, is drastically reduced in the $m c y B$ mutant at both the protein (not shown for $\mathrm{MrpB}$ ) and the mRNA level. We conclude that the down-regulation of $m r p A$ and $m r p B$ expression is directly or indirectly caused by the lack of microcystin in two independent mutants.

MrpA and MrpB show significant similarities to the RhiA and RhiB proteins of Rhizobium leguminosarum, respectively. While effects on nodulation, especially in the absence of nodFEL, have been observed in $R$. leguminosarum, the biochemical role of these proteins remains unclear (Gray et al., 1996). The genes rbiA and $r h i B$, together with $r h i C$, form an operon which is located on the sym plasmid and is flanked by nifH and the nod gene cluster (Cubo et al., 1992). Several plasmids of different sizes exist in M. aeruginosa (Schwabe et al., 1988; E. Dittmann \& G. Christiansen, unpublished data). Although the localization of $\operatorname{mrp} A B$ has not been investigated it is known that the mcy genes encoding the microcystin synthetase reside on the chromosome (Tillett et al., 2000).

The RhiA protein is one of the most abundant cytoplasmic proteins in $R$. leguminosarum (Cubo et al., 1992). Similarily, we detected MrpA as one of the most predominant spots in the two-dimensional pattern of protein preparations from M. aeruginosa PCC 7806 wild-type cells. A rhiC homologue is missing in the direct vicinity of $m r p A$ and $m r p B$. In contrast to RhiA and $\mathrm{RhiB}$, a periplasmic localization is assumed for RhiC (Cubo et al., 1992). A rhiC homologue may well be positioned distinct from mrpAB within the Microcystis genome. Alternatively the function of $\mathrm{RhiC}$ is unnecessary in Microcystis.

Expression of RhiA, B and C is controlled by the RhiR protein, which is a LuxR-type regulator. The LuxR/ LuxI type of quorum-sensing regulation has been shown to control the expression of an increasing number of genes, including peptide synthetase genes, exopolysaccharide genes and virulence factors, especially in host-associated bacteria such as Pseudomonas aeruginosa, Erwinia carotovora and Agrobacterium tumefaciens (Rhizobium tumefaciens) (Whiteley et al., 1999; Bassler, 1999). In Gram-negative bacteria quorumsensing systems consist of an $\mathrm{N}$-acylhomoserine lactone (AHL) signal molecule (autoinducer), which is synthesized by a LuxI homologue, and requires an autoinducer-dependent transcriptional activator protein, as represented by LuxR (Whiteley et al., 1999). At least two different types of AHLs were shown to regulate the rhiABC operon in a cell-density-dependent manner (Rodelas et al., 1999). This type of quorum sensing has not been described for cyanobacteria so far. However, in the natural environment cell-to-cell contact plays an important role for Microcystis and a type of quorum sensing may be required during the formation of a colony habit and of blooms. No evidence exists yet for a role of microcystin as an extracellular signalling molecule. However, the existence of a putative ABC transporter linked to microcystin, as inferred by the identification of a gene homologous to those of known $\mathrm{ABC}$-transporters and located directly upstream of the mcy gene cluster (Tillett et al., 2000), supports the proposal of an active efflux mechanism for microcystin. As significant extracellular amounts of microcystin are detectable, especially under high light (Rapala et al., 1997; E. Dittmann \& M. Kaebernick, unpublished data), this ABC-transporter might be active under these conditions. Such conclusions can also be drawn from preliminary transcription data of the corresponding gene (E. Dittmann, unpublished data). The involvement of efflux pumps in quorum-sensing processes has been postulated not only for AHLs, although diffusible (Whiteley et al., 1999), but also for quinolone as an alternative quorum-sensing mediator (Pesci et al., 1999).

Especially interesting with regard to a function of microcystin is the influence of light on the $\operatorname{mrp} A B$ transcript. Presently, there are no data which indicate a role for light in the expression of rhiABC in $R$. leguminosarum. In PCC 7806 wild-type, the effect of light on $m r p A B$ is seen by strong transcript increases when cells are exposed to blue light. The lack of microcystin in the $m c y B$ mutant leads to a reduction in both the MrpA protein and the level of $m r p A B$ transcripts observed under all light conditions tested. The mutation, however, had no influence on other lightregulated genes $(c p c B A, p s b B)$. The different responses of $\operatorname{mrp} A B$ transcript accumulation by mutant (no response) and wild-type cells (distinct increase) exposed to blue light indicate the microcystin-dependent nature of $\operatorname{mrp} A B$ transcription. Therefore, it appears that the presence of microcystin is a pre-condition for the blue light effect on $m r p A B$ expression. In contrast to the wellinvestigated mechanisms sensing cell density in other bacteria, bloom-forming cyanobacteria may sense light intensity and/or quality and use this mechanism to control production and (possibly) export of microcystin. Microcystin in turn may act under high-light conditions as an intercellular signal. However, $m r p A B$ is not directly regulated by extracellular microcystin, as seen for rhiABC regulated by AHLs. Since the addition of microcystin to the mutant cells did not restore the wildtype transcription level, there could either be another key factor which is regulated by microcystin, or the intracellular microcystin proportion may be somehow involved in the regulation of $m r p A B$; alternatively, microcystin reception could be affected due to the lack of microcystin in the mutants. We conclude that additional light-sensing mechanisms may exist in bloom-forming cyanobacteria, which share features with quorum-sensing mechanisms of other bacteria.

\section{ACKNOWLEDGEMENTS}

We thank Professor G. A. Codd (University of Dundee, UK) for providing us with microcystin-LR. This work was supported by grants from: the DFG (BO1045/13-3) and EU (ENV4-CT98-0802, CYANOTOX) for T. Börner; from the DFG (DO270-8) for H. von Döhren; a DAAD scholarship of 
M. Kaebernick; and from the ARC to B. A. Neilan and M. Kaebernick.

\section{REFERENCES}

Bassler, B. L. (1999). How bacteria talk to each other: regulation of gene expression by quorum sensing. Curr Opin Microbiol 2, 582-587.

Carmichael, W. W. (1994). The toxins of cyanobacteria. Sci Am 270, 78-86.

Chorus, I. \& Bartram, J. (1999). Toxic Cyanobacteria in Watera Guide to their Public Health Consequences, Monitoring and Management. London: E. \& F. N. Spon.

Cubo, M. T., Economou, A., Murphy, G., Johnston, A. W. \& Downie, J.A. (1992). Molecular characterization of the rhizosphere-expressed genes rhiABCR that can influence nodulation in Rhizobium leguminosarum biovar viciae. J Bacteriol 174, 4026-4035.

Dittmann, E., Neilan, B. A., Erhard, M., von Döhren, H. \& Börner, T. (1997). Insertional mutagenesis of a peptide synthetase gene that is responsible for hepatotoxin production in the cyanobacterium Microcystis aeruginosa PCC 7806. Mol Microbiol 26, 779-787.

Gray, K. M., Pearson, J. P., Downie, J. A., Boboye, B. E. \& Greenberg, E. P. (1996). Cell-to-cell signaling in the nitrogenfixing bacterium Rhizobium leguminosarum: autoinduction of a stationary phase and rhizosphere-expressed genes. J Bacteriol 178, 372-376.

Jochimsen, E. M., Carmichael, W. W., An, J. S. \& 9 other authors (1998). Liver failure and death after exposure to microcystins at a hemodialysis center in Brazil. N Engl J Med 38, 873-878.

Kaebernick, M., Neilan, B. A., Börner, T. \& Dittmann, E. (2000). Light and the transcriptional response of the microcystin biosynthetic genes. Appl Environ Microbiol 66, 3387-3392.

Kaneko, T., Tanaka, A., Sato, S., Kotani, H., Sazuka, T., Miyayima, N., Sugiura, M. \& Tabata, S. (1995). Sequence analysis of the genome of the unicellular cyanobacterium Synechocystis sp. strain PCC 6803. I. Sequence features in the $1 \mathrm{Mb}$ region from map positions $64 \%$ to $92 \%$ of the genome. DNA Res $2,153-166$, 191-198.

Namikoshi, M. \& Rinehart, K. L. (1996). Bioactive compounds produced by cyanobacteria. J Ind Microbiol 17, 373-384.

Neilan, B. A., Jacobs, D. \& Goodman, A. E. (1995). Genetic diversity and phylogeny of toxic cyanobacteria determined by DNA polymorphisms within the phycocyanin locus. Appl Environ Microbiol 61, 3875-3883.

Nishizawa, T., Asayama, M., Fujii, K., Harada, K. I. \& Shirai, M. (1999). Genetic analysis of the peptide synthetase genes for a cyclic heptapeptide microcystin in Microcystis sp. J Biochem 126, 520-529.

Nishizawa, T., Ueda, A., Asayama, M., Fujii, K., Harada, K., Ochi, K. \& Shirai, M. (2000). Polyketide synthase gene coupled to the peptide synthetase module involved in the biosynthesis of the cyclic heptapeptide microcystin. J Biochem 127, 779-789.

Orr, P. T. \& Jones, G. J. (1998). Relationship between microcystin production and cell division rates in nitrogen-limited Microcystis aeruginosa cultures. Limnol Oceanogr 43, 1604-1614.
Otto, A., Thiede, B., Müller, E. C., Scheler, C., Wittmann-Liebold, B. \& Jungblut, P. (1996). Identification of human myocardial proteins separated by two-dimensional electrophoresis using an effective sample preparation for mass spectrometry. Electrophoresis 17, 1643-1649.

Perry, R. D., Balbo, P. B., Jones, H. A., Fetherston, J. \& DeMoll, D. E. (1999). Yersiniabactin from Yersinia pestis: biochemical characterization of the siderophore and its role in iron transport and regulation. Microbiology 145, 1181-1190.

Pesci, E. C., Milbank, J. B., Pearson, J. P., McKnight, S., Kende, A. S., Greenberg, E. P. \& Iglewski, B. H. (1999). Quinolone signaling in the cell-to-cell communication system of Pseudomonas aeruginosa. Proc Natl Acad Sci U S A 96, 11229-11234.

Pitkin, J. W., Panaccione, D. G. \& Walton, J. D. (1996). A putative efflux pump encoded by the TOXA gene of the plant-pathogenic fungus Cochliobolus carbonum. Microbiology 142, 1557-1565.

Rapala, J., Sivonen, K., Lyra, C. \& Niemelä, S. I. (1997). Variation of microcystins, cyanobacterial hepatotoxins, in Anabaena spp. as a function of growth stimuli. Appl Environ Microbiol 63, 2206-2212.

Rippka, R. (1988). Recognition and identification of cyanobacteria. Methods Enzymol 167, 28-67.

Rodelas, B., Lithgow, J. K., Wiesniewski-Dye, F., Hardman, A., Wilkinson, A., Economou, A., Williams, P. \& Downie, J. A. (1999). Analysis of quorum-sensing-dependent control of rhizosphereexpressed (rhi) genes in Rhizobium leguminosarum bv. viciae. J Bacteriol 181, 3816-3823.

Rohrlack, T., Dittmann, E., Henning, M., Börner, T. \& Kohl, J. G. (1999). Role of microcystins in poisoning and food ingestion inhibition of Daphnia galeata caused by the cyanobacterium Microcystis aeruginosa. Appl Environ Microbiol 65, 737-739.

Runnegar, M. T., Kong, S. \& Berndt, N. (1993). Protein phosphatase inhibition and in vivo hepatotoxicity of microcystins. Am J Physiol 265, 224-230.

Sambrook, J., Fritsch, E. F. \& Maniatis, T. (1989). Molecular Cloning: a Laboratory Manual, 2nd edn. Cold Spring Harbor, NY : Cold Spring Harbor Laboratory.

Scheler, C., Lamer, S., Pan, Z., Li, X. P., Salnikow, J. \& Jungblut, P. (1998). Peptide mass fingerprint sequence coverage from differentially stained proteins on two-dimensional electrophoresis patterns by matrix assisted laser desorption/ionisation spectrometry (MALDI-MS). Electrophoresis 19, 918-927.

Schwabe, W., Weihe, A., Börner, T., Henning, M. \& Kohl, J. G. (1988). Plasmids in toxic and nontoxic strains of the cyanobacterium Microcystis aeruginosa. Curr Microbiol 17, 133-137.

Shi, L., Carmichael, W. W. \& Kennelly, P. J. (1999). Cyanobacterial PPP family proteins possess multifunctional cababilities and are resistant to microcystin-LR. J Biol Chem 274, 10039-10046.

Tillett, D., Dittmann, E., Erhard, M., von Döhren, H., Börner, T. \& Neilan, B. A. (2000). Structural organization of microcystin biosynthesis in Microcystis aeruginosa PCC 7806: an integrated peptide-polyketide synthase system. Chem Biol 7, 753-764.

Whiteley, M., Lee, K. \& Greenberg, E. P. (1999). Identification of genes controlled by quorum sensing in Pseudomonas aeruginosa. Proc Natl Acad Sci U S A 96, 13904-13909.

Received 27 April 2001; revised 9 August 2001; accepted 13 August 2001. 